\title{
CULTURA, POLÍtica E MODERNIDADE EM NOEL ROSA
}

\author{
Antonio Pedro Tota \\ Professor de História Contemporânea do Departamento de História da PUC-SP
}

\begin{abstract}
Resumo: A produção musical de Noel Rosa, embora importante, é pouco notada pelo meio acadêmico. A obra deste artista demonstra (evidencia ou participa das) as mudanças na estrutura estética da música popular e, principalmente, consegue captar as transformações da sociedade em época de transição.

Palavras-chave: modernidade; urbanização; samba.
\end{abstract}

$\mathrm{N}$ o plano estético, Noel de Medeiros Rosa, ou simplesmente Noel, foi um dos que livrou o samba do ritmo amaxixado, dando uma pontuação mais elaborada e em sintonia com o processo de urbanização. No plano das representações, sua obra pode ser um adequado instrumento para se pensar o paradoxo tradicional/ moderno em nosso país. Por exemplo, quando o cinema falado tomava o lugar do mudo, Noel compôs, em 1932, São coisas nossas, uma clara referência ao primeiro filme falado brasileiro - Coisas nossas (Catani e Souza, 1983). A letra do samba revela a tensão entre o moderno e o tradicional, num quase lamento pelo processo de urbanização da sociedade brasileira:

Queria ser pandeiro/ prá sentir o dia inteiro/ a tua mão na minha pele a batucar/ Saudade do violão e da palhoça/ Coisa nossa... coisa nossa (...).

A sensualidade e a musicalidade da mão tocando na pele do pandeiro/corpo brasileiro despontam a saudade daquilo que está distante e impossível de ser revertido, isto é, o Brasil do sertão, da vida simples e do bucólico da palhoça. A repetição enfatiza a nossa peculiar modernização. Os versos seguintes desnudam a razão básica de nossas contradições:

O samba, a prontidão e outras bossas,/ São nossas coisas... São coisas nossas!

Além da bossa e do samba, a prontidão também é coisa nossa. No jargão popular, a palavra pronto significa sem dinheiro e, na música de Noel, o termo prontidão é usado com um claro sentido indicador da miséria, condição da maioria da população brasileira.

Baleiro, jornaleiro/ Motorneiro, condutor e passageiro/ Prestamista e vigarista/ E o bonde que parece uma carroça/ Coisa nossa, coisa nossa (...).

Personagens urbanos, vivendo no limite do miserê (miséria), corporificados nas "profissões", no cotidiano. Profissões de deserdados, de um lumpenproletariado subproduto da modernidade. Baleiro e jornaleiro - "profissões" de homens sem profissão.

A idéia de que o Rio de Janeiro é a cidade do ócio (sempre tendo como contraponto São Paulo, a cidade do trabalho) (Fausto, 1976) parece se confirmar naquele começo da década de 30: Noel coloca sentados, lado a lado, no bonde da modernidade, o prestamista e o vigarista. $\mathrm{O}$ primeiro pode ser identificado tanto com aquele que compra a prestação como com o agiota que empresta a juros extorsivos, explorando os já explorados, enquanto o vigarista, com sutis diferenças, tem aqui quase que o mesmo sentido do agiota: tanto um como outro evitam o caminho mais árduo do batente, para a sobrevivência. Nada de labuta. Nada da inserção no conflito capital-trabalho.

$\mathrm{O}$ bonde e a carroça. O primeiro é o próprio ícone da modernidade coletivizadora lembrado por um João do Rio, na realidade carioca, ou cantado por um Mário de Andrade, na sua paulicéia desvairada. Eletricidade, apitos de fábricas, chaminés madrugadoras, gramofones e rádios são, afinados ao bonde, os elementos da modernidade. Já o se- 
gundo ícone - a carroça - simboliza o Brasil-sertão-colonial e essencialmente agrário.

Menina que namora/ Na esquina e no portão/ Rapaz casado com dez filhos, sem tostão/ Se o pai descobre o truque dá uma coça/ Coisa nossa, muito nossa!

Tensão no mundo material, tensão no mundo afetivo. Menina que namora no portão guarda restos do namorico inocente, em que o toque de mão seria o gesto mais lúbrico e sacana ( tua mão na minha pele a batucar). Esse namorico inocente de portão é posto em cheque com a revelação do namorado rapaz casado com dez filhos (e o que é pior, sem tostão).

Noel é o crítico da sociedade burguesa e de suas contradições em meio ao impacto da modernidade. Burguesia que carecia de uma verdadeira identidade burguesa, isto é, sem a tradição das burguesias forjadas nas lutas liberais de moldes europeus. Daí sua tendência ao mimetismo. Pode-se dizer que essa classe média só vai adquirir identidade com a futilidade proporcionada pela mídia impressa, radiofonisada e depois televisiva das décadas de 50 e 60.

Noel, como extraordinário crítico da sociedade, é também o flaneur moderno que atribui à multidão uma alma. $\mathrm{O}$ artista valia-se de métodos modernos para denunciar o impacto da modernidade. O moderno, em certos momentos, como limitador das manifestações lúdicas do amor, pode ser combatido com a própria modernidade. É o caso de Três apitos, composição de 1933:

Quando o apito/ Da fábrica de tecidos/Vem ferir os meus ouvidos/ Eu me lembro de você

Pois você anda/Sem dúvida bem zangada/ E está interessada/ Em fingir que não me vê

Você que atende ao apito/ De uma chaminé de barro/ Por que não atende ao grito tão aflito/ Da buzina do meu carro?

Sou do sereno/ Poeta muito soturno (...).

O flaneur luta contra o apito da fábrica de tecidos, utilizando outro instrumento da modernidade: a klaxon, isto é, a buzina.

Os duelos baudelerianos davam-se entre o proletariado-esgrimista e a modernidade burguesa que o gestava e o aniquilava de um só golpe (Berman, 1989). No Brasil, Noel se aproxima mais da proposta oswaldiana, que apresenta o boêmio ( sou do sereno) como o contrário do burguês e não o proletário clássico, expropriado da mais valia marxista. Daí o automóvel, outro ícone da modernidade individualizadora, símbolo da velocidade amorosa dos modernistas/futuristas, usado contra os apitos das chaminés que ferem os ouvidos do homem sensível às transformações antilúdicas amorosas.
Diz-se que Noel tinha ciúme de um guarda-noturno que namorava Josefina, a musa inspiradora de Três apitos. Noel dividia a tecelã com o guarda-noturno, mas tinha outros amores também numa confusão de paixões e desilusões que, sem dúvida, o inspiraram na composição de várias canções:

Mas você sabe/ que enquanto você faz pano/ Faço junto ao piano/ Esses versos prá você.

Relações afetivas pessoais cruzando com a crítica social. Em 1931, Noel entrou em contato com Erastótenes Frazão, importante homem de teatro do Rio de Janeiro e freqüentador da Praça Tiradentes, onde estavam localizados o teatro Recreio, vários bares e cafés, ponto de encontro de compositores, jornalistas, artistas, malandros e trabalhadores do teatro. Frazão foi apresentado a Noel por Nássara, ${ }^{1}$ chargista e conhecido compositor-boêmio carioca, campeão de concursos de músicas carnavalescas. Frazão convidou Noel para trabalhar em Café com músi$c a$, peça inspirada nos bares que serviam café e incluíam, no cardápio, apresentações de sambas de novos compositores. Para a peça de Frazão, Noel compôs Quem dá mais (ou Leilão do Brasil):

Quem dá mais?/ Por uma mulata que é diplomada/ Em matéria de samba e de batucada/ Com as qualidades de moça formosa/ Fiteira e vaidosa, e muito mentirosa

Cinco mil réis, duzentos mil réis, um conto de réis!/ Ninguém dá mais de um conto de réis?/ O Vasco paga o lote na batata/ em vez de barata/ Oferece ao Russinho uma mulata (...).

O primeiro "artigo" brasileiro a ser oferecido é a mulata, logo na primeira estrofe. Noel dá um tratamento à temática que faria arrepiar os estudiosos de gênero e, principalmente, os de etnias, num momento em que o chamado multiculturalismo está em voga. Será fácil fazer uma crítica ao compositor de Vila Isabel sem levar em conta sua época. Mas o tom absolutamente melancólico do leiloeiro que apregoa o "artigo" (tento relativizar o Noel politicamente incorreto com as aspas) sugere ao ouvinte que ele não quer se "desfazer" do "produto". A mulata metamorfoseada em Brasil insere-se na economia de mercado numa antecipação às privatizações feitas, sintomaticamente, em leilões multinacionais: as qualidades são anunciadas e os lances são repetidos monotonamente. Diplomada em matéria de samba e de batucada. A sensualidade da mulher brasileira é, mesmo num samba mais "político", tema recorrente: feiticeira, vaidosa... Foram essas qualidades das brasileiras que fizeram Waldo Frank, o intelectual socialista americano da Política da Boa Vi- 
zinhança (Frank, 1943), repensar, 11 anos depois, as relações de gênero que trazia de seu país. Claro que às qualidades referidas somava-se a mentira que, para Noel, era positivo ( $A$ mulher que não mente não tem valor, do samba Mentir [Mentira necessária] de 1932 gravado por Mário Reis). Quem levou a mulata foi o português do Vasco. Segundo Omar Jubran (2000), no irrepreensível trabalho de recuperação da obra do Poeta da Vila, Russinho, "jogador de futebol mais popular do Brasil”, havia sido premiado com uma barata da Chrysler, como eram chamados os automóveis esportivos na época. Mas Noel troca semanticamente a barata por uma mulata, e passa na segunda estrofe a oferecer outro produto, marca da brasilidade:

(...) Quem dá mais.../ Por um violão que toca em falsete,/ Que só não tem braço, fundo e cavalete/ Pertenceu a dom Pedro, morou no palácio/ Foi posto no prego por José Bonifácio

Vinte mil réis, vinte e um e quinhentos, cinqüenta mil réis!/ Quem arremata o lote é um judeu/ quem garante sou eu/ Pra vendê-lo pelo dobro no museu (...).

Noel sugere nossa desestruturação cultural: o violão tocando em falsete, um violão que só existe na metáfora. $\mathrm{O}$ artigo foi posto no prego pelo patriarca da independência, como forma de levantar fundos para tapar os buracos da nossa dívida externa feita por D. Pedro. O lote, talvez de violões que pertenceram ao imperador, foi arrematado por um judeu. Só mesmo ignorando a História e a historicidade de Noel para acusá-lo de anti-semita, como fez "Jorge Mautner, romancista de Kaos e músico de uma indefinida vanguarda pop [que] preferiu esquecer o Noel compositor e letrista" (Máximo e Didier, 1990:491). Isto porque, em Cordiais saudações, Noel já havia se empenhado nas mãos de um judeu: "Estimo que este mal traçado samba/ Em estilo rude na intimidade/ (...) A vida lá em casa está horrível/ Ando empenhado nas mãos de um judeu". E o leilão do Brasil continua:

Quem dá mais.... quem dá mais?/ Quem dá mais de um conto de réis?/ Dou-lhe uma, dou-lhe duas, doulhe três/ Quanto é que vai ganhar o leiloeiro/ Que também é brasileiro/ Que em três lotes vendeu o Brasil inteiro/ Quem dá mais?????

À venda estava o Brasil lúdico, do samba que exprime dois terços do Rio de Janeiro, expressão da singularidade cultural brasileira. Assim, Noel aponta, seguindo uma tradição de pensadores do porte de Dunshee de Abraches, Manoel Bomfim, Silva Jardim e Lima Barreto, a submissão de uma classe dominante em relação ao capital estrangeiro.

A dívida externa, a nossa dependência e o sentido do progresso foram objetos de várias outras composições do autor em vôo solo ou em parceria. Em 1933, Noel compôs com Orestes Barbosa Positivismo que, como pode ser depreendido pelo título, não tinha como fonte de inspiração nenhum objeto mais prosaico:

A verdade meu amor mora num poço/É Pilatos lá na bíblia quem nos diz/ e também faleceu por ter pescoço/ O inventor da guilhotina em Paris

Vai orgulhosa querida/ Mas aceita esta lição:/ No câmbio incerto da vida/ A libra sempre é o coração/ $\mathrm{O}$ amor vem por princípio/ A ordem por base/ O progresso é que dever vir por fim/ Desprezaste esta lei de Augusto Comte/ E foste viver feliz longe de mim/ Vai coração que não vibra/ Com teu juro exorbitante/ Transformar mais esta libra/ Em dívida flutuante.

O progresso enaltecido pelo positivismo liga-se à guilhotina jacobina. O nosso jacobinismo, o da República da Espada, não conseguiu livrar-nos da dívida externa em libra acumulada pelos vários empréstimos. Os juros eram exorbitantes. A Revolução de 1930 retomou a política de valorização do café, produto em queda no mercado consumidor internacional arrasado pela profunda crise do capitalismo. A política de valorização do café, pela queima ou destruição da safra, alterou, ainda que não profundamente, o quadro. A dívida foi postergada: o governo Vargas tomou algumas medidas que contrariavam os interesses dos credores internacionais.

A destruição do café e a crise geral brasileira foram mote para outra canção de Noel. Em Samba da boa vontade, composto em parceria com João de Barro, em 1931, são apontadas, por meio de uma fina ironia, as mazelas de país dependente em época de crise internacional. A música composta por Braguinha e Noel era contemporânea dos acontecimentos decorrentes da Revolução de 1930:

(...) Viver alegre hoje é preciso/ conserva sempre o teu sorriso/ Mesmo que a vida esteja feia/ e que vives na pinimba/ Passando a pirão de areia

(...) Comparo meu Brasil/ A uma criança perdulária/ que anda sem vintém/ Mas tem a mãe que é milionária/ E que jurou, batendo o pé/ Que iremos à Europa/ Num aterro de café.

Clara referencia à malversação de nossas riquezas. Riqueza e pobreza eram temas presentes em praticamente toda obra de Noel. Filosofia, samba de 1933, é um dos muitos exemplos: "Mas a filosofia/ Hoje me auxilia/ A viver indiferente assim/ Nesta prontidão sem fim/ vou fingindo que sou rico/ Pra ninguém zombar de mim." Porém, a riqueza e a pobreza, em Samba da boa vontade, referiam-se ao país e não ao indivíduo. A riqueza jogada no mar, ou seja, o café faria um aterro que daria para che- 
gar na Europa (Jubran, 2000:24). Riqueza de país monocultor-colonial em meio à pobreza generalizada.

Para além da crítica social, a obra de Noel está cheia de signos pessimistas. Mesmos nas canções compostas com certo humor, percebe-se o crescente uso de temas como tristeza, pobreza, felicidade, infelicidade, saúde, paixão, etc. Já em Cordiais saudações, samba de 1931, cantado por Noel acompanhado pelo Bando de Tangarás, o tratamento melancólico da melodia é acentuado pela interpretação do autor:

Estimo que este mal traçado samba/ Em estilo rude, na intimidade/ Vá te encontrar gozando saúde/ Na mais completa felicidade.

O defeito físico de Noel - o queixo afundado - ficava mais notável com a fase adulta e, por isso, evitava grandes reuniões sociais. Entretanto, ele tornava-se cada vez mais conhecido pelas suas músicas. Aos 22 anos já era uma figura pública. Como flaneur buscava nos bares, botequins e cabarés, cada vez mais, seu refúgio. Nestes lugares há uma certa identidade de objetivos dos frequientadores: a busca da felicidade mesmo que efêmera, como pode ser visto em Quem ri melhor, samba de 1936:

Pobre de quem já sofreu nesse mundo/ a dor de um amor profundo/ Eu vivo bem sem amar a ninguém/ Ser feliz é sofrer por alguém/Zombo de quem sofre assim/ Quem me fez chorar hoje chora por mim/Quem ri melhor é quem ri no fim.

Numa festa, a anfitriã não conseguiu esconder o espanto diante do defeito físico do compositor. Noel sentiu, e compôs a canção, já mencionada, Mentir (Mentira necessária):

Mentir, mentir somente para esconder/ A mágoa que ninguém deve saber/ Mentir, mentir, em vez de demonstrar/ a nossa dor num gesto ou num olhar/ Saber mentir é prova de nobreza

Para não ferir alguém com a franqueza/ Mentira não é crime/ É bem sublime o que se diz/ Mentindo pra fazer alguém feliz.

A máscara e a face. Uma saída afetiva para serem contornadas as mazelas de uma alma ferida. Em Fita amarela, o conflito entre os opostos inseparáveis, isto é, a vida e a morte:

Quando eu morrer/ não quero choro nem vela

(...) Se existisse alma/ si há outra encarnação/ eu queria que uma mulata/ Sapateasse no meu caixão.

Morte anunciada atenuada pela sensualidade. A mulata dançando sobre o caixão representa a vida erotizada. A música de Fita amarela não chega a sugerir algo melancólico, imprimindo vida à letra que fala da morte.

Depois que Noel encontrou Oswaldo Gogliano, o Vadico, as composições ficaram ainda mais melancólicas e pessimistas. É o que acontece com Feitio de oração, a primeira canção que fizeram juntos, música de Vadico e letra de Noel:

Quem acha vive se perdendo/ Por isso agora eu vou me defendendo/ Da dor tão cruel desta saudade/ Que por infelicidade/ $\mathrm{O}$ meu peito invade.

A cada dia Noel consumia mais álcool. Cervejas e biritas, na expressão de Aracy de Almeida, eram lenitivos e anestésicos para a alma perturbada do poeta. Boêmio, ia dormir muito tarde. Chegava em casa com o sol nascendo. Alimentava-se mal. Começava a trabalhar por volta das 5 horas da tarde. Ia para um bar encontrar outros compositores, ou a uma estação de rádio ou gravadora. A vida amorosa do boêmio Noel era coerente com a busca angustiante de si mesmo: de namoricos no portão às paixões arrrebatodoras pelas damas de cabarés. Uma tocou fundo seu coração, tratava-se de Ceci. Porém, o namoro "sério" foi com Lindaura, mulher de 17 anos, cuja mãe acusou Noel de sedução de menor de idade: ou casa ou vai para a cadeia. Noel preferiu cadeia (Máximo e Didier, 1990:280). $\mathrm{O}$ artista parecia responder, aos que exigiam dele uma satisfação, com sambas como Capricho de rapaz solteiro:

Nunca mais essa mulher/ me vê trabalhando/ Quem vive sambando/ Leva a vida para o lado que quer/ De fome não se morre/ Nesse Rio de Janeiro/ Ser malandro é capricho de rapaz solteiro/ A mulher é um achado/ Que nos perde e nos atrasa/ Não há malandro casado/ Pois malandro não se casa.

A pressão familiar, de ambos os lados, não deixou outra saída senão o casamento. Aos 23 anos, sem festas, Noel parecia entrar em contradição, pois malandro não se casa. Talvez Noel fosse um malandro às avessas, como as letras de suas canções Malandro medroso e João Ninguém. Mesmo assim, encarava o casamento como simples acidente.

Na luta interna que se travava no interior de sua alma, Tanatos parecia levar a melhor sobre Eros. Noel tinha seus pulmões tomados pela tuberculose, doença que atingia parcela considerável dos boêmios. Na mesma proporção que a doença avançava, a situação na casa parecia cada dia mais insuportável. Dinheiro cada vez mais escasso e Lindaura, a esposa, queria trabalhar. Noel respondeu:

Você vai se quiser/ Pois a mulher/ Não se deve obrigar a trabalhar/ mas não vá dizer depois/ que você não tem vestido/ E o jantar não dá pra dois (...).

O médico de Noel, Dr. Graça Melo, sabia que a única saída era a mudança radical de estilo de vida. Isto era impossível para o poeta/moderno/esgrimista que se entregava à boemia, em especial onde trabalhava Ceci, sua amada do cabaré. Eram atitudes suicidas afinadas com a posição 
do "herói moderno". Mesmo assim, fez a tentativa: seguiu o conselho do médico e mudou de ares. Foi para Belo Horizonte e, da capital mineira, escreveu ao Dr. Graça Melo:

Já apresento melhoras,/ Pois levanto muito cedo/ E ...deitar as nove horas/ Para mim é brinquedo

A injeção me tortura/ E muito medo me mete/ Mas minha temperatura/ Não passa de trinta e sete! (...)

Creio que fiz muito mal/ Em desprezar o cigarro/ Pois não há material/ Para o exame de escarro! (...).

Em Belo Horizonte começou a trabalhar na Rádio Mineira e entrou em contato com compositores, voltando novamente para a noite boêmia. Belo Horizonte tornouse pequena para o herói suicida. Voltou para o Rio de Janeiro dizendo-se curado. Tuberculose curava-se com tratamento prolongado e o de Noel foi rapidíssimo, ou seja, não estava curado. Voltou a freqüentar os bares e a trabalhar na composição de novas canções. No Bar do Ponto, o Dr. Graça Mello encontrou o compositor e o alertou, mas Noel continuou sua saga. Encontrava-se com mais frequiência com Ceci, a dama do cabaré. Ela tentava evitálo, pois tuberculose era facilmente transmissível. Noel, sentindo-se rejeitado, compôs:

Provei do amor todo o amargor/ Que ele tem/ Então jurei/ Nunca mais amar ninguém (...)

$\mathrm{O}$ pai, que estava internado num sanatório, havia se enforcado. Aliás, o suicídio fazia parte da história da família. Durante a juventude do compositor, a avó havia se enforcado em uma árvore no quintal do "chalé modesto". Profundamente deprimido, Noel bebia, fumava e emagrecia rapidamente.

Tentou, ainda por duas vezes, mudar de ares, mas a proximidade da morte de um poeta angustiado deixava claro que era inútil. No Rio de Janeiro, no chalé com a família, sentado na cadeira, pouco se movimentava.

Almirante (1977) registrou em No tempo de Noel Rosa - livro clássico para os estudiosos da música brasileira os últimos momentos do poeta da Vila:

"No dia 4 de maio [1937] na rua Teodoro da Silva no 385 festejava-se o aniversário de Dona Emília, esposa do violonista Vicente Gagliano (...) Pela noite adentro ouviase o conjunto de Heitor que, entre diversos números populares, não deixava de executar as músicas de Noel (...)

Por volta das 21:30hs, enquanto D. Marta [mãe de Noel] e Lindaura no portão se despediam de amigos da família, seu irmão Hélio, vigilante à cabeceira notou que o doente abria os olhos esgazeadamente (...)

Ao fazer um movimento, a mão de Noel se estendeu para a mesinha da cabeceira, em cujo tampo (...) ficou batendo pancadas surdas, ritmadas, esmorecendo (...) Por fim a mão de Noel se quedou imóvel” (Almirante, 1977:213).

Aracy de Almeida e Benedito Lacerda tinham acabado de gravar, naquela mesma noite, Eu sei sofrer, uma das últimas composições de Noel:

Quem é que já sofreu mais do que eu/ quem é que já me viu chorar?/ Sofrer foi um prazer que Deus me deu/ Eu sei sofrer sem reclamar/ Quem sofreu mais do que eu não nasceu/ Com certeza Deus já me esqueceu

Mesmo assim não cansei de viver/ E na dor eu encontro prazer/ Saber sofrer é uma arte/ E pondo a modéstia de parte,/ Eu posso dizer que sei sofrer (...)

Conflito, crítica e pessimismo estiveram sempre presentes em grande parte da obra de Noel Rosa. Mesmo nas canções mais hilariantes e humoradas, denota-se um certo pessimismo. Conflito entre a vida e a morte. Os limites entre Eros e Tanatos. A poesia conflituosa do poeta urbanista. Noel fraquejava diante das forças superiores da modernidade que pesavam sobre seus ombros. Forças desproporcionais. Baudelaire, Balzac, Nietzche sentiram o mesmo. Suicídio e modernidade. Suicídio não como fuga covarde. Benjamin suicidou-se... Não fazer concessões ao ambiente que é hostil ao artista. Tal suicídio não é desistência, mas heróica paixão (Benjamin, 1985; Berman, 1989).

\section{NOTAS}

E-mail do autor: totapedro@uol.com.br

1. Em entrevista concedida ao autor, em maio de 1978, Nássara confirmou a versão entremeada de vários episódios pitorescos.

\section{REFERÊNCIAS BIBLIOGRÁFICAS}

ALMIRANTE. No tempo de Noel Rosa. $2^{\mathrm{a}}$ ed. Rio de Janeiro, Livraria Francisco Alves, 1977.

BENJAMIN, W. “A modernidade”. In: KOTHE, F.R. (org.). Paris do Segundo Império em Baudelaire. São Paulo, Ática, 1985 (Coleção Grandes Cientistas Sociais).

BERMAN, M. Tudo que é sólido desmancha no ar - a aventura da modernidade. São Paulo, Cia. das Letras, 1989.

CATANI A.M. e SOUZA, J.I. de M. A chanchada no cinema brasileiro. São Paulo, Brasiliense, 1983.

FAUSTO, B. Trabalho urbano e conflito social. São Paulo/Rio de Janeiro, Difel, 1976.

FRANK, W. South American Journey. Nova York, Duell, Sloan and Pearce, 1943

JUBRAN, O.A.J. Noel pela primeira vez. Brasília, Funarte - Ministério da Cultura, 2000 (livreto).

MÁXIMO, J e DIDIER, C. Noel Rosa, uma biografia. Brasília, Ed. Universidade de Brasília, 1990. 